\title{
A novel curcumin-based vaginal cream Vacurin selectively eliminates apposed human cervical cancer cells
}

\author{
Priya Ranjan Debata a,c , Mario R. Castellanos ${ }^{\text {c,d }}$, Jimmie E. Fata ${ }^{\text {b,c }}$, Sarah Baggett a,c \\ Sritha Rajupet c,d , Anita Szerszen ${ }^{\text {c,d }}$, Sultana Begum ${ }^{\text {a,c }}$, Anita Mata ${ }^{\text {a,c }}$, Vundavalli V. Murty ${ }^{\text {, }}$ \\ Lynne M. Opitz ${ }^{\text {e }}$, Probal Banerjee ${ }^{\text {a,c,* }}$ \\ a Department of Chemistry, The College of Staten Island (CUNY), USA \\ ${ }^{\mathrm{b}}$ Department of Biology, The College of Staten Island (CUNY), USA \\ c The Biomedical Laboratories for Integrative Cancer Research at CSI-SIUH (BLICaR), The College of Staten Island (CUNY), USA \\ d Department of Medicine, Staten Island University Hospital (North Shore-LIJ Health System), USA \\ e Department of Pathology and Laboratory Medicine, Staten Island University Hospital (North Shore-LIJ Health System), USA \\ ${ }^{\mathrm{f}}$ Department of Pathology and Institute for Cancer Genetics, Irving Cancer Research Center, Columbia University Medical Center, USA
}

\section{H I G H L I G H T S}

- The study shows the selective efficacy of the spice component curcumin in eliminating HPV $(+)$ human cervical cancer cells.

- It develops a curcumin-based vaginal cream, Vacurin-20, and demonstrates its efficacy in eliminating apposed cervical cancer cells.

- This preclinical study establishes Vacurin-20 as a safe medication in an in vivo mouse model.

\section{A R T I C L E I N F O}

\section{Article history:}

Received 11 September 2012

Accepted 3 December 2012

Available online 9 December 2012

\section{Keywords:}

Curcumin

Cervical cancer

EGF receptor

p53

$\mathrm{Rb}$

Human papillomavirus

\begin{abstract}
A B S T R A C T
Objective. Human papillomavirus (HPV) infections remain a leading cause of mortality worldwide. In the U.S. strategies via screening and vaccination prevent HPV-associated cervical neoplasms, but consume immense healthcare costs. The spice component curcumin has potent anticancer and antiviral properties, which have been difficult to harness as a treatment, due to its poor systemic bioavailability. This project tests the possibility of developing a curcumin-based therapy for cervical cancer.

Methods. Using four $\mathrm{HPV}(+)$ cervical cancer cell lines and normal fibroblasts we first tested the selectivity and potency of curcumin in eliminating $\mathrm{HPV}(+)$ cells. Subsequently, we developed a curcumin-based cervical cream and tested its efficacy in eliminating apposed $\mathrm{HPV}(+)$ cells and also its possible side effects on the vaginal epithelium of healthy mice.

Results. Curcumin selectively eliminates a variety of $\mathrm{HPV}(+)$ cervical cancer cells (HeLa, ME-180, SiHa, and SW756), suppresses the transforming antigen E6, dramatically inhibits the expression of the pro-cancer protein epidermal growth factor receptor (EGFR), and concomitantly induces p53. Additionally, Vacurin, a uniform colloidal solution of curcumin in a clinically used amphipathic vaginal cream, eliminates apposed HeLa cells while suppressing the expression of EGFR. In mice, daily intravaginal application of Vacurin for three weeks produced no change in body weight and when the mice were sacrificed, the vaginal tract epithelium showed no Vacurin-evoked adverse effects.

Conclusion. We have developed a curcumin-based vaginal cream, which effectively eradicates $\operatorname{HPV}(+)$ cancer cells and does not affect non-cancerous tissue. Our preclinical data support a novel approach for the treatment of cervical HPV infection.

(c) 2012 Elsevier Inc. All rights reserved.
\end{abstract}

\footnotetext{
* Corresponding author at: Department of Chemistry and the Center for Developmental Neuroscience, The City University of New York at The College of Staten Island, Staten Island, NY, 10314, USA. Fax: +1 7189823944.

E-mail address: probal.banerjee@csi.cuny.edu (P. Banerjee).
}

\section{Introduction}

Cervical cancer is a leading cause of cancer death amongst females worldwide, of which the human papillomavirus (HPV) is the main etiologic risk factor [1]. By the age of $50,75-80 \%$ of sexually active women have acquired HPV at some point in their lifetime, making it the most common sexually transmitted disease in the United States [2]. In developed countries, cervical cancer screening programs have 
been effective in reducing cancer mortality [3]. But the annual cost to treat HPV-associated pre-cancers is in the order of billions of dollars in the U.S. [4]. Precancerous lesions of the cervix can be identified early and treated. In women of reproductive age, loop electrosurgical excision procedure (LEEP) is the most common strategy used to treat high-grade dysplasia. Though LEEP is a very effective treatment option, it comes with some risk. Cervical incompetence and preterm delivery are potential consequences that affect future obstetrical outcomes [5,6]. In a promising recent report, using the Toll-like receptor 7 agonist imiquimod in a phase II clinical trial, regression of CIN 2-3 lesions and HPV infection were demonstrated with 16 weeks of intravaginal application of this compound [7] Though promising, not all HPV associated lesions were cleared in this study. Therefore, a universally effective treatment for cervical HPV infection does not exist. The introduction of the two prophylactic HPV vaccines, Cervarix ${ }^{\circledR}$ or Gardasil ${ }^{\circledR}[8]$ offers promise to prevent the most common oncogenic HPV types 16/18-associated cervical lesions, but efficacy is achieved only in HPV-naïve patients [3] as the vaccines are not therapeutic. Additionally, in developing nations with limited economic resources or poor healthcare infrastructure, vaccination programs may not be feasible. Thus, despite significant advances in prevention, screening and treatment, cervical HPV infection remains a major cause of morbidity and mortality of women worldwide. Therefore, examining agents harboring antiviral and/or antitumor properties against HPV-associated lesions remains as an important focus.

Curcumin, a yellow pigment from the root of Curcuma longa linn is a natural inexpensive component derived from the Southeast Asian spice turmeric. Clinical studies have demonstrated that oral administration of curcumin is safe and well-tolerated with no significant toxicity and an acceptable blood chemistry profile [9-11], but its use is limited by its low systemic bioavailability $[12,13]$. Nevertheless, curcumin's potential role in cancer therapy continues to be investigated in clinical trials for several types of cancer [9,10,14-16]. Experiments in cell culture systems and animal models have established curcumin's antitumor [14], anti-inflammatory [14], and anti-viral properties [17-19]. Such studies have shown that curcumin treatment of HPV-infected cells rapidly inhibits the expression of HPV-E7, a key oncoprotein involved in tumor growth and malignant transformation and also restores the levels of the cell cycle regulators p53 and retinoblastoma protein $(\mathrm{Rb})$ [17]. Like many other HPV positive cervical cancer cells, the cell lines used here HeLa, ME-180, SiHa, and SW756 harbor the wild-type p53 protein [20,21]. Both cell cycle inhibitors $\mathrm{p} 53$ and $\mathrm{Rb}$ are suppressed in most cancer cells, and expression of increased levels of these proteins has been linked to regression of cervical cancer [22-24]. Therefore, any curcumin-evoked induction in p53 and/or Rb could be effective in derailing the cells from cell cycle and cancer growth. This is the first hypothesis that has been tested in the current study.

Curcumin has been used to eliminate cervical cancer cells in laboratory experiments, but its use in the treatment of cervical cancer has had limited success, partially because of its low solubility in water $[12,13]$. We postulate that intravaginal application of a curcumin-based amphipathic cream may be a safe alternative with the potential for improved efficacy. We demonstrate here that a colloidal mixture of curcumin in a vaginal cream is able to eliminate juxtaposed cancer cells in culture without any adverse effect on the lower reproductive tract in a mouse model.

\section{Materials and methods (see Supporting Information for details)}

Animals

All animals were handled and used for surgery following an experimental protocol approved by the Institutional Animal Care Committee (IACUC) of the College of Staten Island (CUNY).

\section{Cell culture}

Human dermal fibroblast cells (ATCC) were procured and cultured using fibroblast growth supplements and $1 \%$ penicillin-streptomycin (PS). HeLa (HPV-18 +), ME-180 (HPV-68+), SiHa (HPV-16+), and SW756 (HPV-18 +) cells [20,21,25-27] were obtained from ATCC and cultured in Dulbecco's Modified Eagles Medium (DMEM) containing $10 \%$ fetal bovine serum (FBS) and 1\% PS.

\section{Curcumin}

(Please see Supporting Information for details on source and solubilization).

\section{Curcumin treatment and WST-1 assay}

The general methods have been reported earlier [28,29]. Further details have been included in the Supporting Information.

\section{Western blot analysis}

The general procedure has been reported in our earlier publications $[28,29]$. (Please see Supporting Information for details).

\section{Immunofluorescence staining}

The general procedure has been reported in our earlier publications [28,29]. (Please see Supporting Information for details).

\section{Vaginal curcumin formulation}

Intravaginal formulation containing $2 \%, 5 \%, 10 \%$ and $20 \%(\mathrm{w} / \mathrm{w})$ curcumin were prepared by mixing curcumin powder with a commercially available topical oil-in-water cream base called Vanicream (Pharmaceutical Specialties, Inc., Rochester, MN). These formulations were named as Vacurin-2, Vacurin-5, Vacurin-10, and Vacurin-20, respectively. Our tests showed that $5 \mathrm{~g}$ of Vacurin occupied a volume of $5 \mathrm{ml}$. Therefore, in the rest of this report, we have expressed the concentrations of curcumin in Vacurin as $20 \%$ (w/v). The two components were thoroughly mixed using a spatula and the homogeneity of the mixture was verified by visualizing curcumin fluorescence at $530 \mathrm{~nm}$ using a Leica Laser Confocal Scanning System (Exton, PA) TCS SP2.

\section{Toxicity tests for Vanicream and Vacurin-20 in mice}

Three-month-old female mice in three groups were intravaginally treated with intravaginal infusions of PBS, Vanicream or Vacurin-20. Group\#1 received PBS alone, Group\#2 received Vanicream alone and Group\#3 received Vacurin-20. The mouse vaginal tract volume was measured and observed to be around $10 \mu$ l. Therefore, approximately $10 \mu \mathrm{L}$ of either PBS, Vanicream or Vacurin-20 were infused using a fire-polished pasture pipette into the vagina every morning at 9:30 AM. The applications were continued daily for two weeks after which the body weight of each mouse was determined. To minimize variations in inflammation, mouse vaginal smears were monitored and each mouse was euthanized at the first proestrus stage following the last treatment [30]. Subsequently, the uterus-cervix and vagina were dissected in its entirety as a single specimen, fixed in $10 \%$ formalin, sectioned into sagittal sections, and stained with hematoxylin and eosin ( $\mathrm{H} \& \mathrm{E})$ for histopathologic examination by a pathologist (L.M.O).

\section{Statistical analysis}

Please see Supporting Information. 


\section{Results}

Curcumin causes a decrease in cell viability as assessed by morphological analysis as well as WST-1 assay

Cultured human cervical cancer cells of four clonal origins, HeLa, ME-180, SiHa, and SW756, were efficaciously eliminated by curcumin. Based on WST-1 assays, the IC50 concentrations were $17 \mu \mathrm{M}$ (HeLa), $12 \mu \mathrm{M}$ (ME-180), $51 \mu \mathrm{M}$ (SiHa), and $21 \mu \mathrm{M}$ (SW756), respectively. In sharp contrast only high concentrations of curcumin $(\geq 100 \mu \mathrm{M})$ caused a significant decrease in WST-1 activity in the primary human fibroblasts (Fig. 1).

Curcumin causes rapid suppression of Epidermal Growth Factor Receptor (EGFR) and elevation of the cell cycle inhibitor p53

Discrete signaling proteins mediate transformation, survival, and proliferation of various types of cancer cells. Curcumin disrupts signaling or expression of a key signaling protein specific to a cancer cell type rapidly, even before any cell degeneration is visible. Thus,
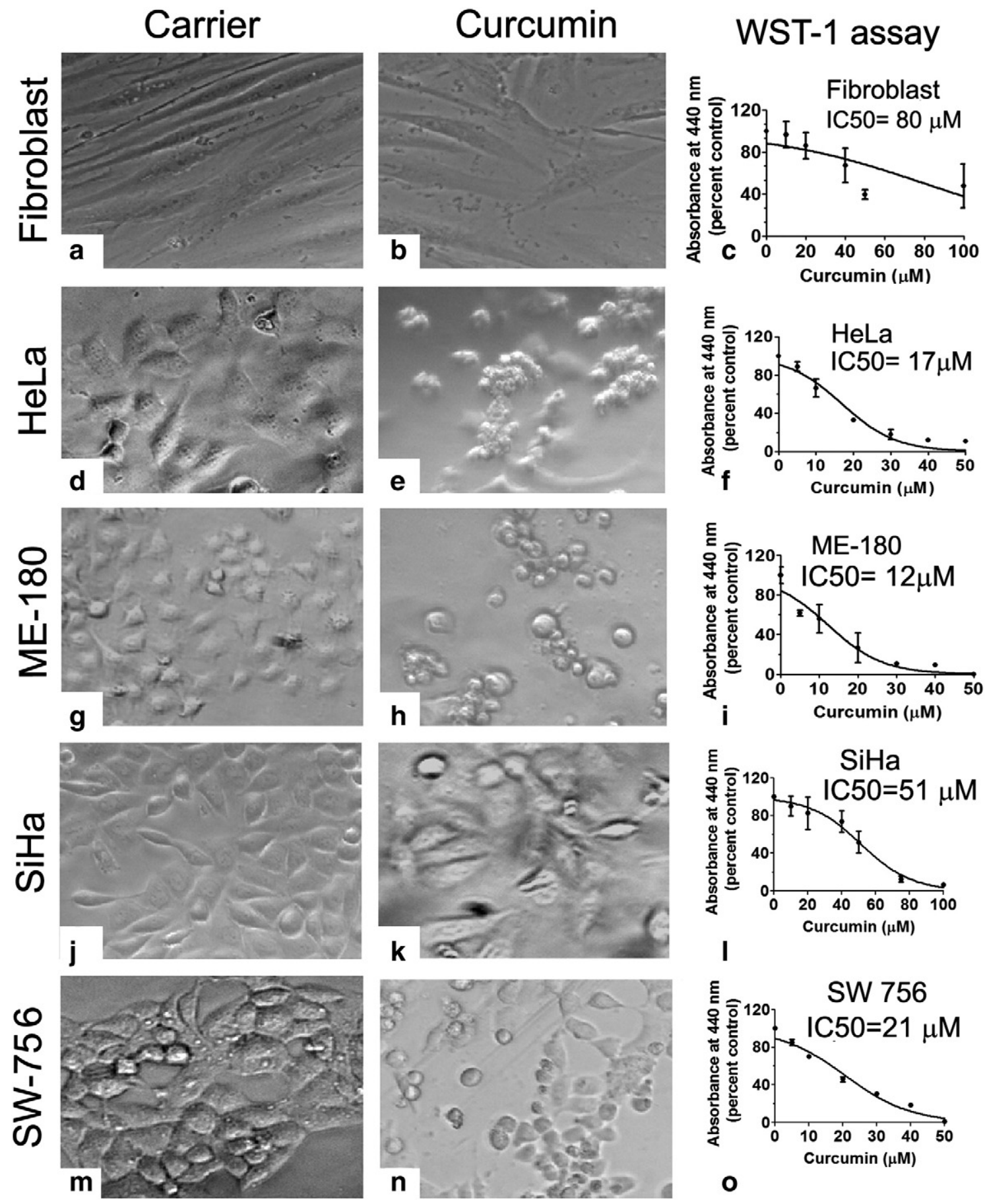

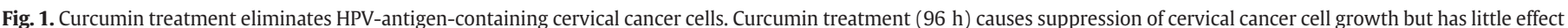

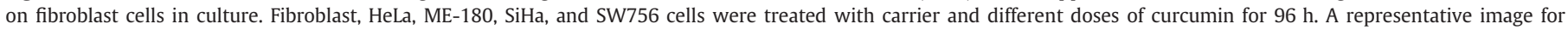

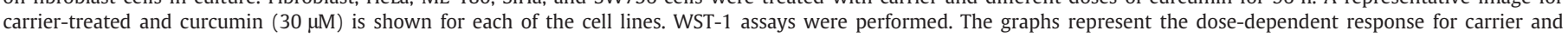
curcumin on the different cell lines used in the study. The IC50 value indicated in each graph was obtained from two experiments, each performed with triplicate samples. 
NF-kB is rapidly inhibited in the melanoma or glioblastoma cells by curcumin within $8 \mathrm{~h}$ of treatment [28,31]. Most notably, in these cervical cancer cells, epidermal growth factor receptor (EGFR) is dramatically suppressed by curcumin within 8 h (Fig. 2). Simultaneously, curcumin treatment elicits elevated expression of the cell cycle inhibitor p53 (Fig. 2). A concomitant inhibition of serine-780 phosphorylation $\mathrm{Rb}$, which inactivates this cell cycle inhibitor, was also observed in the HeLa and ME-180 cells. The Rb levels were much higher and $\mathrm{P}-\mathrm{S} 780-\mathrm{Rb} / \mathrm{Rb}$ ratio very small in the SiHa and SW756 cells to observe any regulation of phosphorylation.

\section{Curcumin causes suppression of the cell-transforming HPV antigen E6}

Immunohistochemical analysis revealed detectable expression of E6 in all four cervical cancer cell lines, HeLa, ME-180, SiHa, and SW756, but not in the human fibroblast cells (Fig. 3a and Supplementary Fig. 1). Curcumin treatment caused a significant decrease in the expression of E6 in all the four cell lines (Fig. 3b and Supplementary Fig. 1). Similar experiments were also attempted using a wide range of concentrations of a HPV 16 specific monoclonal anti-E7 antibody (cat\# Sc-6981, Santa Cruz Biotechnology, Santa Cruz, CA), but no immunocytochemical staining could be achieved.
Curcumin forms a smooth colloidal solution in the neutral vaginal gel Vanicream

To enable topical application of curcumin in a form that could be readily absorbed by the apposed cells, we tested the miscibility of the hydrophobic molecule curcumin in the amphipathic vaginal gel Vanicream. Up to $20 \% \mathrm{w} / \mathrm{v}$, curcumin formed a uniform colloidal solution in Vanicream (named as Vacurin-20) as evidenced by an increase in fluorescence intensity of a layer of the gel on a microscopic plate at $530 \mathrm{~nm}$. Beyond 20\% (w/v), solid curcumin particles remained and no further increase in fluorescence intensity was observed (Supplementary Fig. 2a and b). Supplementary Fig. 2c shows the uniform yellow color of Vacurin-20.

\section{Cervical cancer cells apposed to Vacurin-20 are eliminated}

To verify if topical application of Vacurin-20 could eliminate cancer cells, Vacurin-2 ( $2 \%$ curcumin), Vacurin-5 (5\% curcumin), Vacurin-10 (10\% curcumin), and Vacurin-20 (20\% curcumin) (100 mg of each) were each placed on a porous $(0.22 \mu \mathrm{m})$ membrane in an 8 -mm tissue culture insert, which was held within $1 \mathrm{~mm}$ from HeLa cells cultured in a $35-\mathrm{mm}$ well of a six-well tissue culture plate. The cells and the

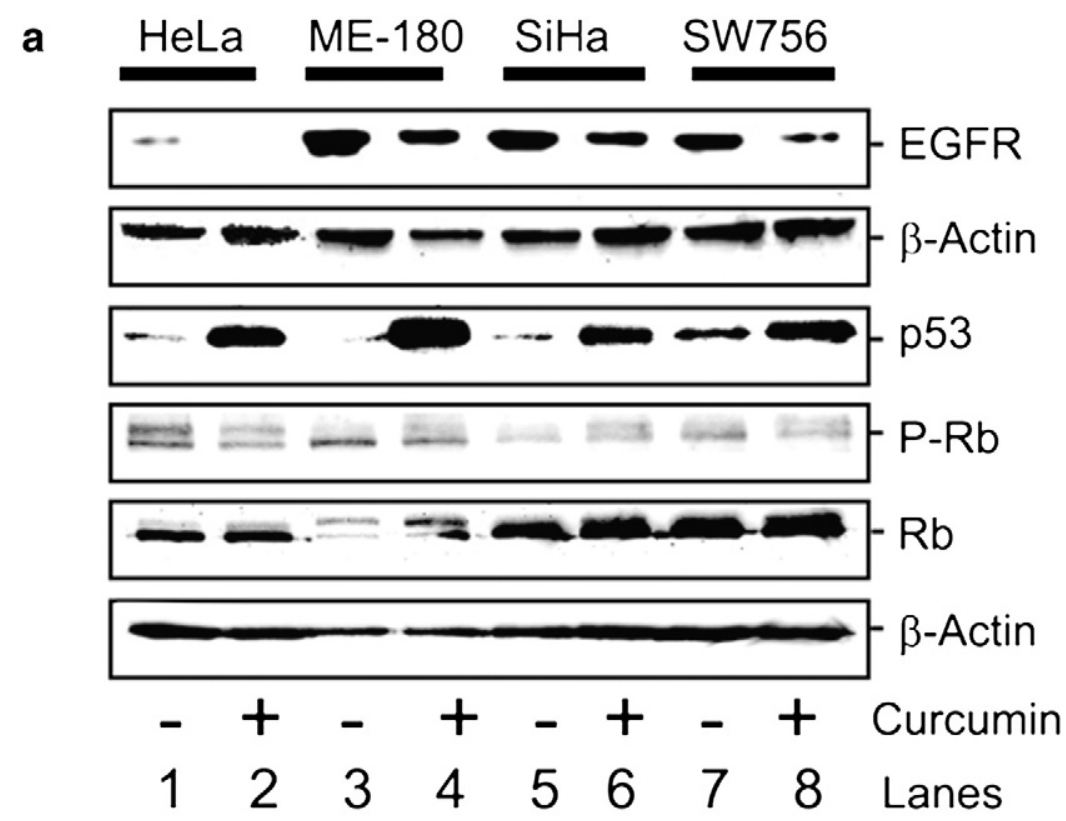

b (i)

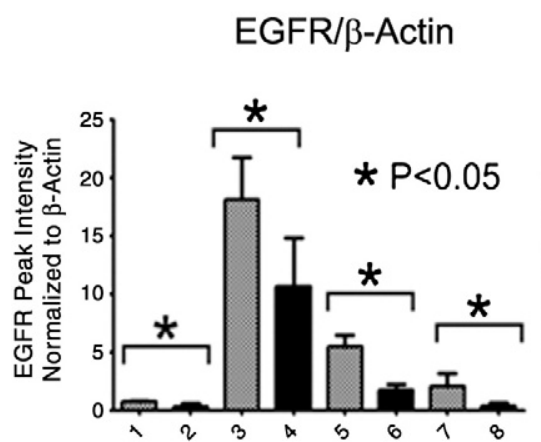

(ii)

$$
\text { p53/ß-Actin }
$$

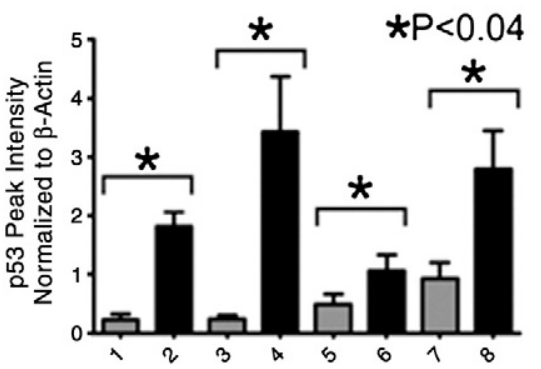

(iii) 
a

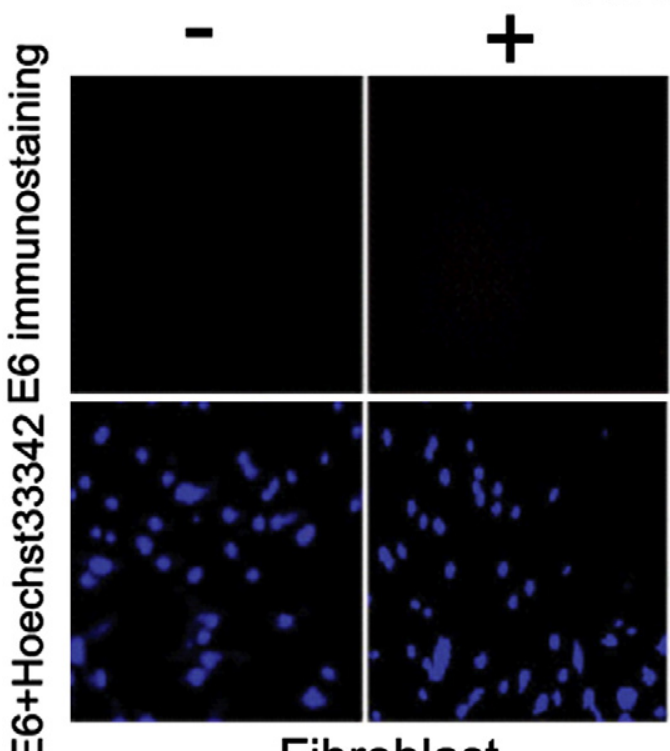

Fibroblast
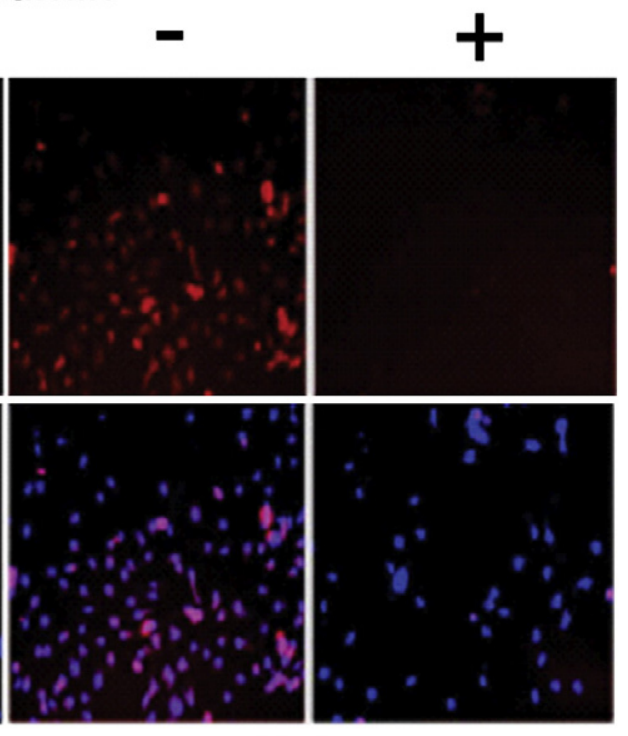

ш

b

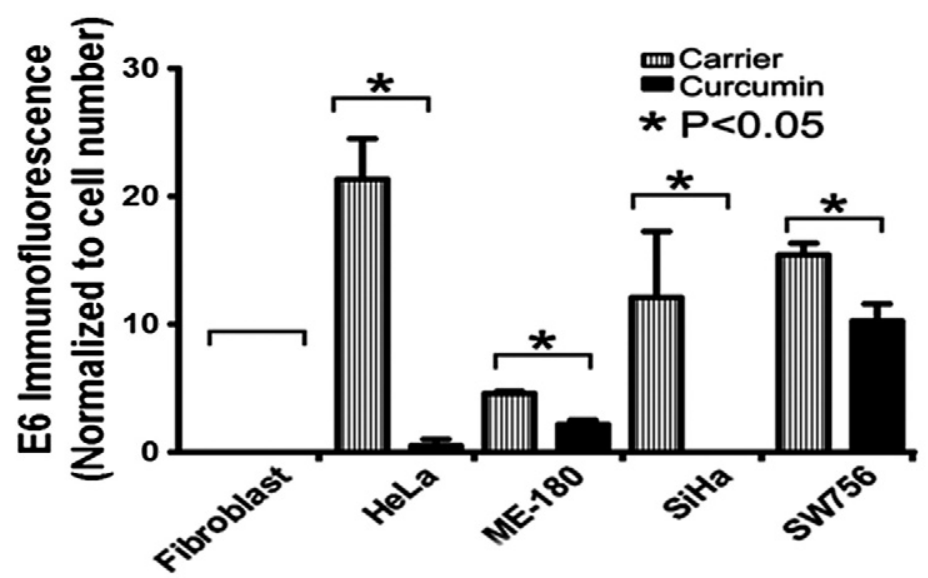

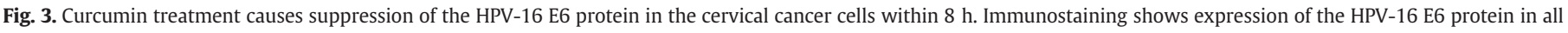

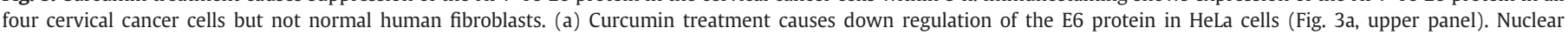

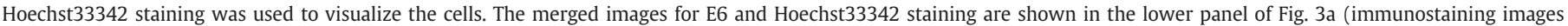

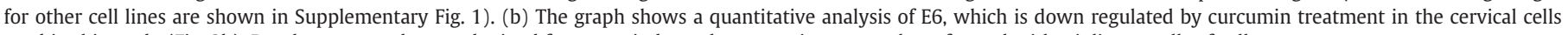
used in this study (Fig. 3b). Results presented were obtained from two independent experiments, each performed with triplicate wells of cells.

membrane were bathed in serum-free DMEM. After $72 \mathrm{~h}$, the cells juxtaposed to the membrane as well as those away from the insert were analyzed by microscopy (Fig. 4a). Vacurin-5, Vacurin-10, and Vacurin-20 caused increasing inhibition of cell number in the immediate vicinity (Fig. 4a and b). In Vacurin-20 treatment, the apposed cells (juxtaposed to the membrane) and in the immediate vicinity were completely eliminated. In contrast, cells at increasing distance from the insert were much less affected by Vacurin and placing Vanicream or solid curcumin on the membrane without the cream caused no cell death at all (Fig. 4a). WST-1 assay performed on the entire well showed a much smaller decrease in activity in Vacurin-20, which demonstrated that Vacurin-20 acted only on cells that were closely apposed to the cream (Fig. 4c).

Vacurin-20 treatment causes suppression of EGF receptor expression and vaginal application of Vacurin-20 yields no detrimental effect

HeLa cells treated for $8 \mathrm{~h}$ with Vacurin-20 showed a significant suppression of EGF receptor expression (Fig. 5a and b).
Vanicream or Vacurin-20 (10 $\mu \mathrm{l}$ mouse) was applied daily to the vaginal tract and cervix of adult C57BL6 female mice. After three weeks of treatment, the Vacurin-20-treated mice appeared indistinguishable from Vanicream-treated and untreated controls in weight (Fig. 5c). In a similar experiment with three mice in each group treated with either intravaginal infusions of PBS or Vanicream or Vacurin-20, the mice were then sacrificed and the lower reproductive tract was removed and saggital sections of the tissue were stained with H\&E. The Vacurin-20-treated mice did not show any increased inflammation compared to the PBS- or Vanicream-treated mice (Fig. 5d and Table 1). The vaginal epithelium of the mice did not show any ulceration, areas of necrosis, or micro-abscess formation. The inflammation noted among the Vacurin-treated mice in the epithelial and stromal regions were not more than that in the control animals, which received either intravaginal PBS or Vanicream. One mouse in the PBS treated group had grade 3 severe inflammation at the distal segment of the vaginal tract, this was possibly due to mechanical trauma during intravaginal infusion, otherwise, all groups had similar histopathologies after vaginal infusion. 
a

Vanicream
alone
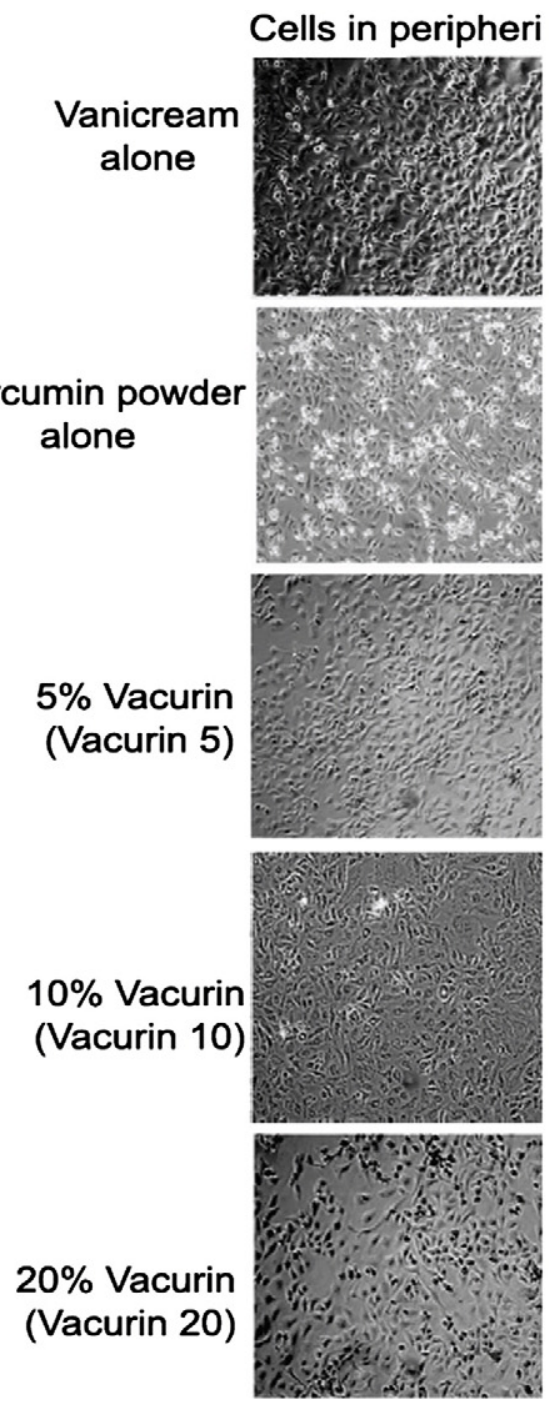

b

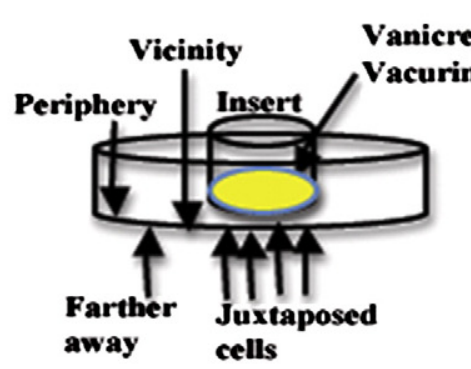

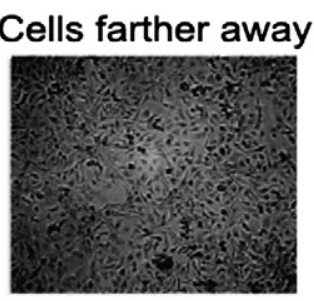
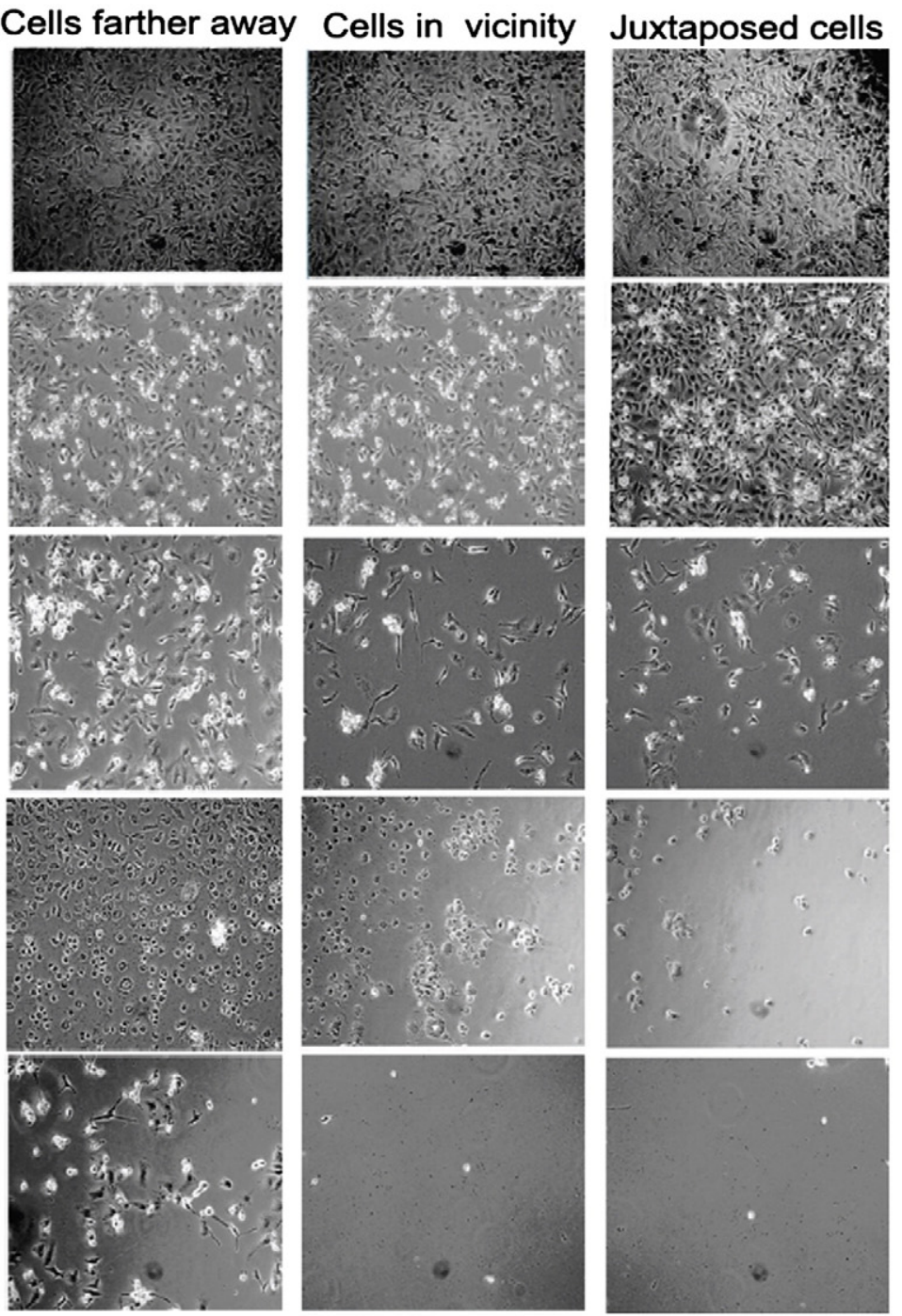

C

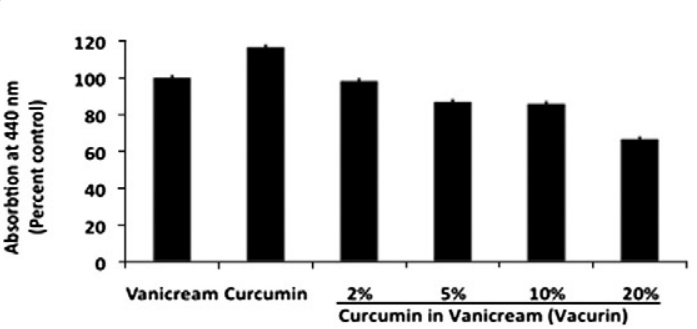

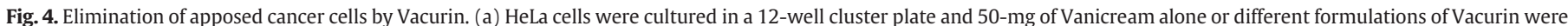

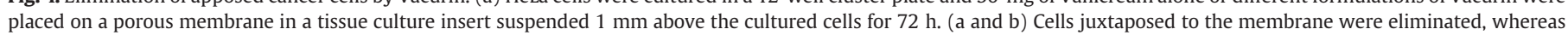
cells located further away were less affected. (c) Peripheral live cells dis-allow a dramatic decrease in WST-1 activity. Data shown are representative of two experiments.

\section{Discussion}

Research to develop anti-viral or anti-tumor therapies for cervical cancer have focused on sophisticated technologies such as immunotherapy, gene therapy, and novel compounds. Although promising, vulnerable populations in developing nations are unlikely to have access to these costly therapies. However, the use of nutraceuticals, like curcumin, may be an effective and low-cost alternative for the prevention and treatment of certain diseases [9,10,14-16]. In view of the promising data for curcumin as an effective anticancer [17] and antiviral agent [17-19], we have developed an intravaginal cream
(Vacurin-20), which is effective in eliminating HPV-associated cervical cancer cell lines. Furthermore, we show Vacurin-20 does not affect non-cancerous cells in our in vitro experiments and in our in vivo mouse model.

Here we first show an interesting mechanistic trend in four $\mathrm{HPV}(+)$ cervical cell lines that harbor wild-type p53 [20,21]. Curcumin caused a rapid inhibition of the cancer-promoting protein EGFR and a simultaneous induction of the cell cycle inhibitor p53 (Fig. 2). Curcumin also blocked phosphorylation of $\mathrm{Rb}$ at serine-780, which inactivates this protein. This unleashed its cell cycle-inhibitor property in HeLa and ME-180 cells (Fig. 2). In contrast, expression 
a

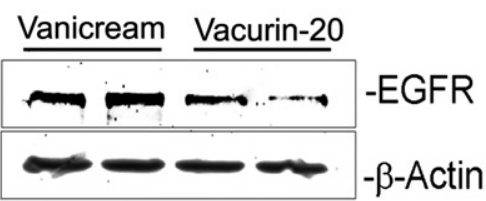

b

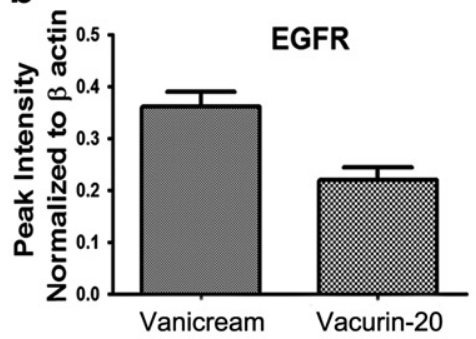

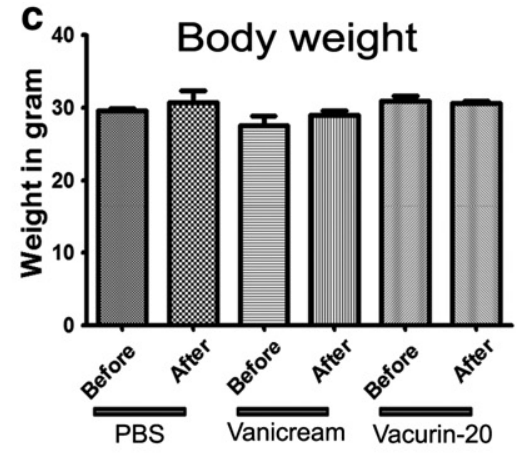

d
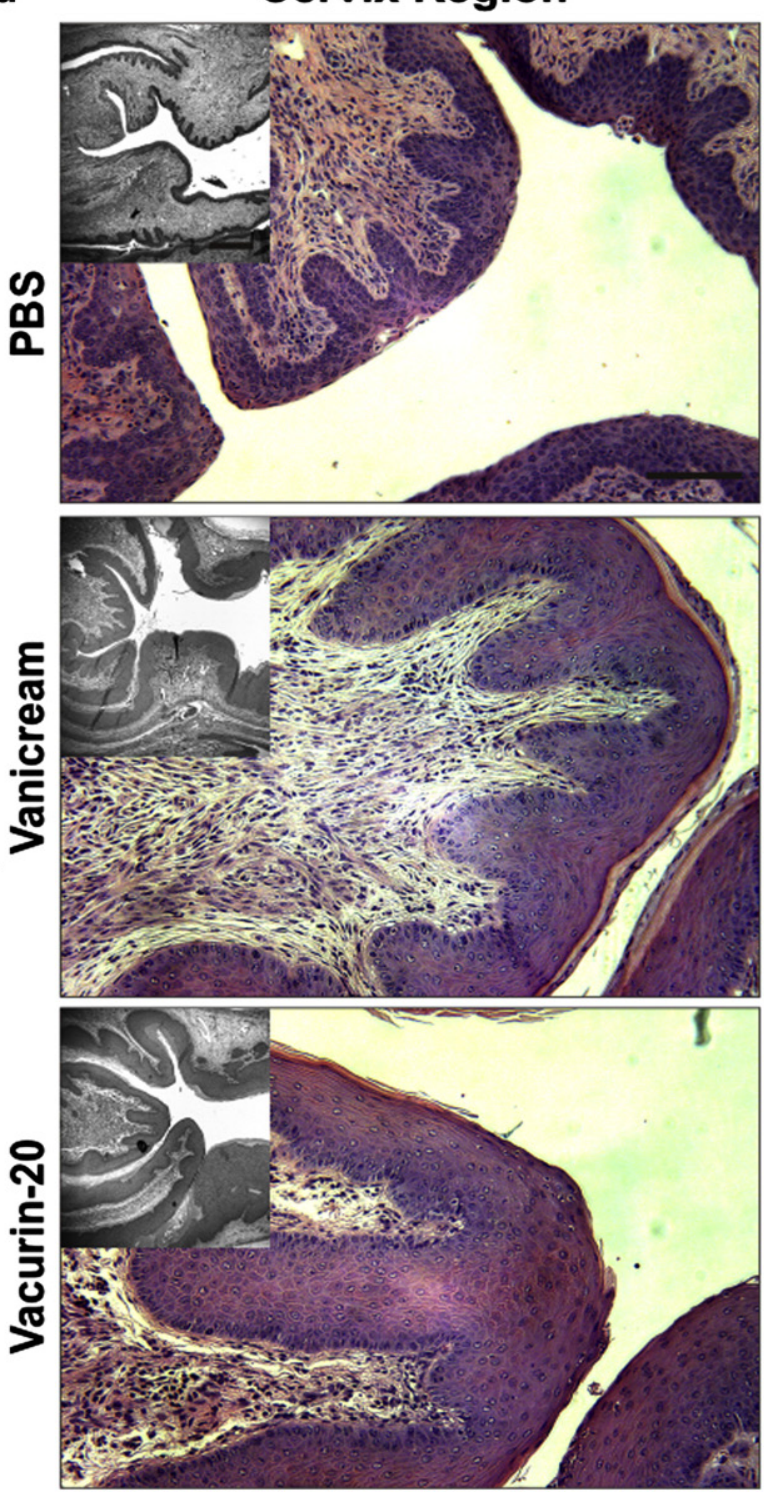

Vaginal Canal
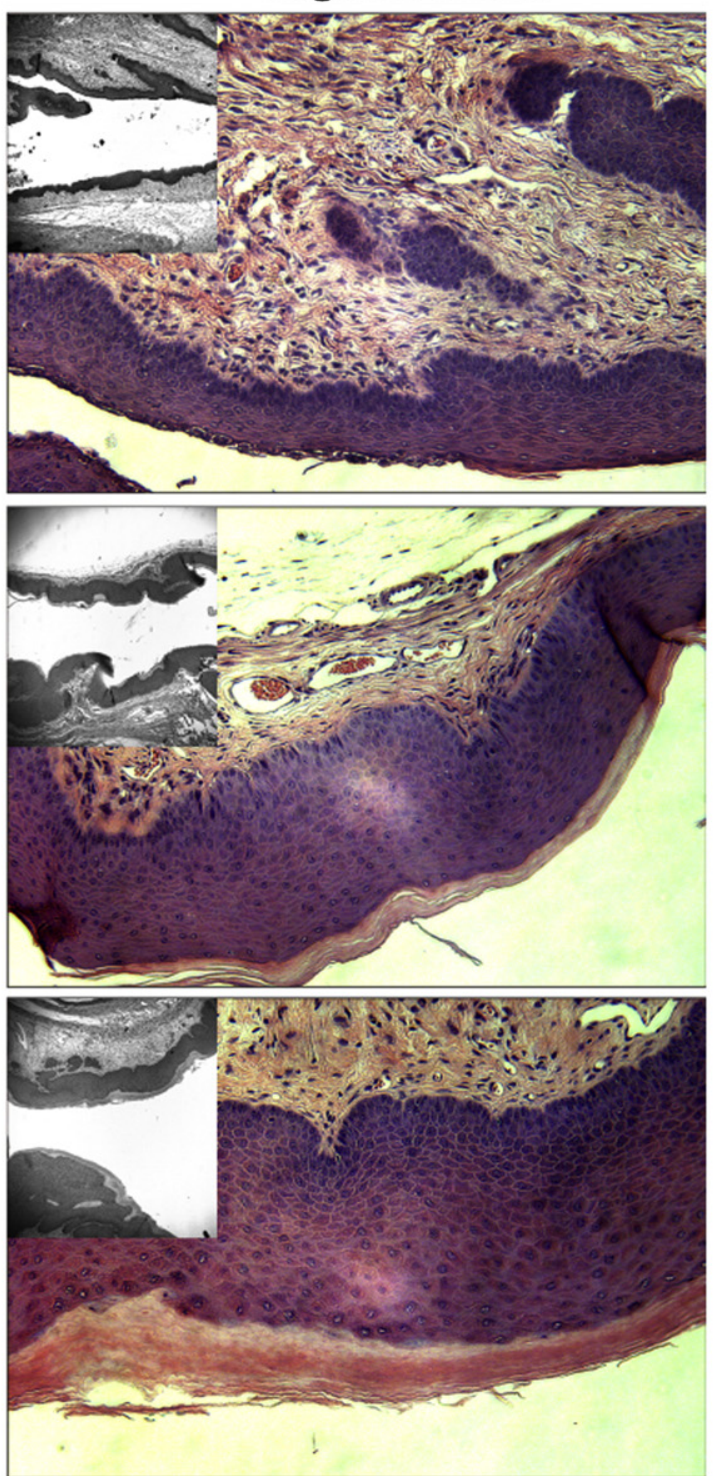

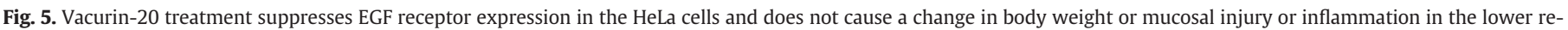

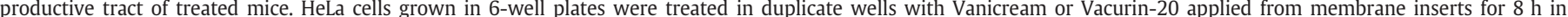

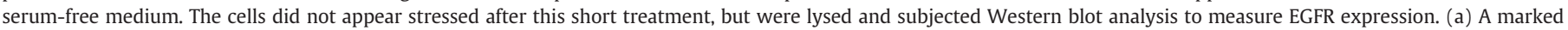

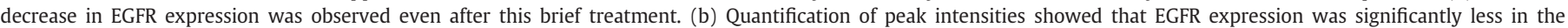

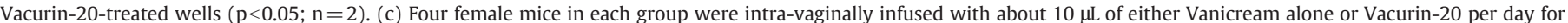

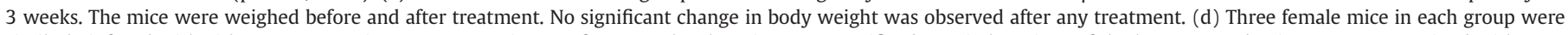

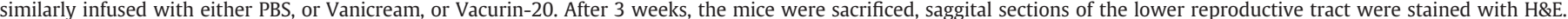

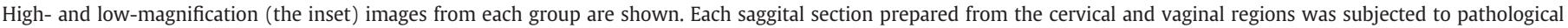

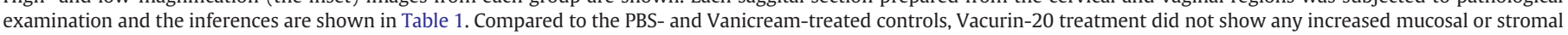
inflammation or injury. 
Table 1

Histopathology of Lower Genital Tract of Treated Mice.

\begin{tabular}{lll}
\hline Intravaginal infusion & Epithelial inflammation & $\begin{array}{l}\text { Stromal } \\
\text { inflammation (grade) }\end{array}$ \\
\hline C1-PBS & Grade 0 & 1 \\
C2-PBS & Grade 1 (distal vaginal canal) & 1 \\
C3-PBS & Grade 3 & \\
& Grade 1-2 (proximal) & 1 \\
Vanicream1 & Grade 0 & 1 \\
Vanicream2 & Grade 0 & 1 \\
Vanicream3 & Grade 1 (distal vaginal canal) & \\
Vacurin-1 & Grade 2 (cervix) & 2 \\
Vacurin-2 & Grade 1 & 1 \\
Vacurin-3 & Grade 1 & 1 \\
\hline
\end{tabular}

Grade $0-$ no inflammatory cells present.

Grade 1 - mild acute inflammation with local areas containing neutrophils.

Grade 2 - moderate inflammation with diffuse areas containing neutrophils.

Grade 3 - severe inflammation with marked areas of inflammatory cells present with focal areas of necrosis

Grade 4 - significant areas of necrosis and inflammation and/or micro-abscess formation.

of Rb was much higher in SiHa and SW756 cells than in HeLa and $\mathrm{ME}-180$, and the $\mathrm{P}-\mathrm{Rb} / \mathrm{Rb}$ ratio was too small even in the absence of curcumin to cause any appreciable inactivation of $\mathrm{Rb}$ in these cell lines (Fig. 2b). So, the curcumin-evoked cell cycle regulation in $\mathrm{SiHa}$ and SW756 cells was likely to be caused through the induction of p53 and inhibition of EGFR.

Earlier studies have used an HPV16-transformed human keratinocyte cell line to show that wild type p53 causes suppression of Sp1- and Yin Yang 1 (YY1)-mediated induction of EGFR [32]. Curcumin treatment causes an induction of p53 in many cancer cell types [33-36] and this increased p53 could cause suppression of EGFR in the four human cervical cancer cell lines used here. Additionally, curcumin, which inhibits histone deacetylase (HDAC) [34,35], could block HDAC-mediated induction of EGFR [33].

The HPV 16 oncoprotein E6, which has been implicated in HPV-mediated transformation of normal cells, is dramatically suppressed by curcumin. The transforming antigens E6 and E7, which complex with p53 and Rb, respectively, trigger degradation of these cell cycle inhibitors $[37,38]$. Thus, in addition to eliminating the HPV-infected cervical cancer cells, by suppressing E6 (and possibly E7) and simultaneously boosting p53 and activating $\mathrm{Rb}$ [17] (Fig. 2), curcumin may also block HPV-associated transformation of cervical cancer cells. Further experiments will reveal if curcumin and Vacurin-20 are effective in suppressing or eliminating other key regulatory HPV proteins like E2, which are essential for viral replication [37,39]. This submits an exciting possibility for the treatment of women with persistent HPV infection who are known to be at high risk for developing severe dysplasia and cancer. Furthermore, topical imidazoquinolines like Aldara, are able to stimulate the immune response and improve antiviral immunity. [40]. In clinical trials, these medications in some patients were to clear HPV infection and cause regression of high grade vulvar and cervical dysplasias. $[7,41]$. Combining these agents to enhance cell-mediated immunity with our curcumin cream to modulate intracellular signaling, could be an attractive approach to target several mechanisms that HPV uses to evade host responses.

The commercially available base Vanicream is free of perfume, lanolin, formaldehyde, parabens, or dyes [36]. It has been used earlier to deliver steroid hormones to the vaginal area [4]. Data presented here establish that our formulation, Vacurin-20, suppresses the same pro-cancer signaling pathways as inhibited by curcumin and effectively eliminates apposed cervical cancer cells. Through mouse studies, we show here that intravaginal application of Vacurin-20 is feasible and safe. The simplicity and inexpensive nature of this strategy is the most important aspect of our research, as this approach is applicable to both developed and developing nations. Its future as a treatment modality for cervical cancer and HPV associated dysplasias is currently being investigated through carefully designed clinical trials. Successful development of a nutraceutical-based cream for clinical use will depend on its stability, ease of application, and reliable anticancer and antiviral properties.

\section{Conflict of interest statement}

The authors declare that there are no conflicts of interest.

\section{Acknowledgment}

We thank Mr. Michael Caputo, Ms. Tzivya Weiss, and Ms. Anumita Das for technical assistance. Ms. Anita Mata received a summer research scholarship from the office of the Dean (CSI).

\section{Appendix A. Supplementary data}

Supplementary data to this article can be found online at http:// dx.doi.org/10.1016/j.ygyno.2012.12.005.

\section{References}

[1] Jemal A, Bray F, Center MM, Ferlay J, Ward E, Forman D. Global cancer statistics. CA Cancer J Clin 2011;61:69-90.

[2] Koutsky L. Epidemiology of genital human papillomavirus infection. Am J Med 1997;102:3-8.

[3] National Cancer Institute. Cancer trends progress report - update 2009/2010. Available at http://progressreport.cancer.gov/doc_detail.asp?pid $=1 \&$ did $=2007 \&$ chid $=$ $72 \&$ coid $=717 \&$ mid=\#benefits. [Accessed July 5, 2012].

[4] Fowler RS. Vulvar vestibulitis: response to hypocontactant vulvar therapy. J Low Genit Tract Dis 2000;4:200-3.

[5] Crane JM. Pregnancy outcome after loop electrosurgical excision procedure: a systematic review. Obstet Gynecol 2003;102:1058-62.

[6] Noehr B, Jensen A, Frederiksen K, Tabor A, Kjaer SK. Loop electrosurgical excision of the cervix and subsequent risk for spontaneous preterm delivery: a population-based study of singleton deliveries during a 9-year period. Am J Obstet Gynecol 2009;201(33):e1-6.

[7] Pachman DR, Barton DL, Clayton AC, McGovern RM, Jeffries JA, Novotny PJ, et al Randomized clinical trial of imiquimod: an adjunct to treating cervical dysplasia. Am J Obstet Gynecol 2012;206(42):e1-7.

[8] Stanely M. Potential mechanisms for HPV vaccine-induced long-term protection. Gynecol Oncol 2010;118:S2-7.

[9] Dhillon N, Aggarwal BB, Newman RA, Wolff RA, Kunnumakkara AB, Abbruzzese JS, et al Phase II trial of curcumin in patients with advanced pancreatic cancer. Clin Cancer Res 2008;14:4491-9.

[10] Sharma RA, Euden SA, Platton SL, Cooke DN, Shafayat A, Hewitt HR, et al. Phase clinical trial of oral curcumin: biomarkers of systemic activity and compliance. Clin Cancer Res 2004;10:6847-54

[11] Steward WP, Gescher AJ. Curcumin in cancer management: recent results of analogue design and clinical studies and desirable future research. Mol Nutr Food Res 2008;52:1005-9.

[12] Anand P, Kunnumakkara AB, Newman RA, Aggarwal BB. Bioavailability of curcumin: problems and promises. Mol Pharm 2007:4:807-18.

[13] Begum AN, Jones MR, Lim GP, Morihara T, Kim P, Heath DD, et al. Curcumin structurefunction, bioavailability, and efficacy in models of neuroinflammation and Alzheimer's disease. J Pharmacol Exp Ther 2008;326:196-208.

[14] Strimpakos A, Sharma RA. Curcumin: preventive and therapeutic properties in laboratory studies and clinical trials. Antioxid Redox Signal 2008;10:511-45.

[15] Kanai M, Yoshimura K, Asada M, Imaizumi A, Suzuki C, Marsumoto S, et al. A phase I/II study of gemcitabine-based chemotherapy plus curcumin for patients with gemcitabine-resistant pancreatic cancer. Cancer Chemother Pharmacol 2011;68:157-64.

[16] Cheng AL, Hsu CH, Lin JK, Hsu MM, Ho YF, Shen TS, et al. Phase I clinical trial of curcumin, a chemopreventive agent, in patients with high-risk or premalignant lesions. Anticancer Res 2001;21:2895-900.

[17] Maher DM, Bell MC, O'Donnell EA, Gupta BK, Jaggi M, Chauhan SC. Curcumin suppresses human papillomavirus oncoproteins, restores p53, Rb, and PTPN13 proteins and inhibits benzo[a]pyrene-induced upregulation of HPV E7. Mol Carcinog 2011;50:47-57

[18] Singh RK, Rai D, Yadav D, Bhargava A, Balzarini J, De Clercq E. Synthesis, antibacterial and antiviral properties of curcumin bioconjugates bearing dipeptide, fatty acids and folic acid. Eur J Med Chem 2010;45:1078-86.

[19] Si X, Wang Y, Wong J, Zhang J, McManus BM, Luo H. Dysregulation of the ubiquitin-proteasome system by curcumin suppresses coxsackievirus B3 replication. J Virol 2007:81:3142-50

[20] Jia L-Q, Osada M, Ishioka C, Gamo M, Ikawa S, Suzuki T, et al. Screening the p53 status of human cell lines using a yeast functional assay. Mol Carcinog 1997;19: 243-53. 
[21] Forbes S, Clements J, Dawson E, Bamford S, Webb T, Dogan A, et al. COSMIC 2005. Br J Cancer 2006;94:318-22.

[22] Baak JPA, Kruse A-J, Garland SM, Skaland I, Janssen EAM, Tabrizi S, et al. Combined p53 and retinoblastoma protein detection identifies persistent and regressive cervical high-grade squamous intraepithelial lesions. Am J Surg Pathol 2005;29:1062-6.

[23] Øvestad IT, Gudlaugsson E, Skaland I, Malpica A, Munk AC, Janssen EAM, et al. The impact of epithelial biomarkers, local immune response and human papillomavirus genotype in the regression of cervical intraepithelial neoplasia grades $2 \mathrm{e} 3$. J Clin Pathol 2011;64:303-7.

[24] Øvestad IT, Gudlaugsson E, Skaland I, Malpica A, Kruse A-J, Janssen EAM, et al Local immune response in the microenvironment of CIN2-3 with and without spontaneous regression. Mod Pathol 2010;23:1231-40.

[25] Harris CP, Lu XL, Narayan G, Singh B, Murty VVVS. Comprehensive molecular cytogenetic characterization of cervical cancer cell lines. Genes Chromosomes Cancer 2003;36:233-41.

[26] Scotto L, Narayan G, Nadula SV, Arias-Pulido H, Subramaniyam S, Schneider A et al. Identification of Copy number gain and overexpressed genes on chromosome Arm 20q by an integrative genomic approach in cervical cancer: potential role in progression. Genes Chromosomes Cancer 2008;47:755-65.

[27] Narayan G, Scotto L, Neelakantan V, Kottoor SH, Wong AHY, Loke S-L, et al. Protocadherin PCDH10, involved in tumor progression, is a frequent and early target of promoter hypermethylation in cervical cancer. Genes Chromosomes Cancer 2009;48:983-92.

[28] Langone P, Debata PR, Dolai S, Curcio GM, Inigo JD, Raja K, et al. Coupling to a cancer cell-specific antibody potentiates tumoricidal properties of curcumin. Int J Cancer 2012;131:E569-78.

[29] Purkayastha S, Berliner A, Fernando SS, Ranasinghe B, Ray I, Tariq H, et al. Curcumin blocks brain tumor formation. Brain Res 2009;1266C:130-8.

[30] Fata JE, Chaudhary V, Khokha R. Cellular turnover in the mammary gland is correlated with systemic levels of progesterone and not 17beta-estradiol during the estrous cycle. Biol Reprod 2001;65:680-8.
[31] Langone P, Curcio GM, Kashfi K, Dolai S, Raja K, Banerjee P. Drug targeting to eliminate breast and brain tumors. Joint AACR and ACS meeting - chemistry in cancer research: the biological chemistry of inflammation as a cause of cancer. San Diego, CA; 2011 [p. January 30, 2011 to February 2, 2011].

[32] Bheda A, Creek KE, Pirisi L. Loss of p53 induces epidermal growth factor receptor promoter activity in normal human keratinocytes. Oncogene 2008;27: 4315-23.

[33] Chou C-W, Wu M-S, Huang W-C, Chen C-C. HDAC inhibition decreases the expression of EGFR in colorectal cancer cells. PLoS One 2011;6:e18087.

[34] Pt Holte, van Emelen K, Janicot M, Fong PC, de Bono JS, Arts J. HDAC inhibition in cancer therapy: an increasingly intriguing tale of chemistry, biology and clinical benefit. Top Med Chem 2007;1:293-331.

[35] Lee SJ, Krauthauser C, Maduskuie V, Fawcett PT, Olson JM, Rajasekaran SA. Curcumin-induced HDAC inhibition and attenuation of medulloblastoma growth in vitro and in vivo. BMC Cancer 2011;11:1-13.

[36] Loyd VA. Featured excipient: topical oil-in-water cream bases. Int J Pharm Comp 2002;6:303-4.

[37] Doorbar J. Molecular biology of human papillomavirus infection and cervical cancer. Clin Sci 2006;110:525-41.

[38] Moon MS, Lee CJ, Um SJ, Park JS, Yang JM, Hwang ES. Effect of BPV1 E2-mediated inhibition of E6/E7 expression in HPV16-positive cervical carcinoma cells. Gynecol Oncol 2001;80:168-75.

[39] Bellanger S, Tan CL, Nei W, He PP, Thierry F. The human papillomavirus Type 18 E2 protein is a cell cycle-dependent target of the $\mathrm{SCF}^{\mathrm{Skp} 2}$ ubiquitin ligase. J Virol 2010;84:437-44.

[40] Fahey LM, Raff AB, Da Silva DM, Kast WM. Reversal of human papillomavirus-specific T cell immune suppression through TLR agonist treatment of Langerhans cells exposed to human papillomavirus type 16. J Immunol 2009;182:2919-28.

[41] van Seters M, van Beurden M, ten Kate FJ, Beckmann I, Ewing PC, Eijkemnans MJ et al. Treatment of vulvar intraepithelial neoplasia with topical imiquimod. N Engl J Med 2008;358:1465-73. 